\title{
Consumption: The Fashionable Disease of the Self and Its Romantic Allure in Literature
}

\author{
Arsto Nasir Ahmed \\ English Department/ Sulaimani University
}

\begin{abstract}
Consumption-Tuberculosis or (TB) -is considered as a peculiarly significant disease across different disciplines. This research traces the medical and literary history of the disease then discusses its aestheticised glamour in a number of writings that date back to the 16th, 17th, 18th and 19th centuries. Before being identified as a lethal disease in the 20th century, consumption was dealt with positively during the preceding periods or eras i.e., being consumptive signified love, easy death, female beauty, male creativity and genius, etc. The specific purpose of this academic endeavour is to answer in detail the questions of why, how and when consumption-as a destructive force- was regarded as a strong cultural device for selffashioning and what made the perception on the disease shift or alter from positive to negative - from an aestheticised, romantic disease to a deadly one.
\end{abstract}

\section{INTRODUCTION}

Consumption is "one of the most historical-as well as historically important - diseases" (Dormandy1). It has a peculiar place in medical and literary history. Suffering from consumption at different periods was viewed as a sign of passion, genius or spirituality. And, the aestheticisation of the disease was reflected in the literary and medical writings of the late eighteenth and the early nineteenth centuries. This research aims to investigate the historical process by which consumption was made the disease of the self for certain social groups. It scrutinises the reasons behind the romantic idealisation of this killer disease in literature. In this spirit, the purpose of this research is to examine how, when and why this lethal killer was considered to be a powerful cultural device for self-fashioning. The research starts with exploring the literary and medical history of the disease. It discusses how and why consumption was regarded as a disease of love and desire in the sixteenth century. Then, it elucidates the reasons behind people's perceptions of the disease as being a way for a good and easy death throughout the late sixteenth and late seventeenth centuries. Later, it goes on to shed light on how and why consumption was thought to be a sign of female beauty, and male creativity and genius in the eighteenth century. Finally, it concludes with mentioning the shift in people's perception to the disease from a positive to a deadly one.

\section{A Historical Overview of Consumption}

In Consumption and Literature: The Making of the Romantic Disease, Clark Lawlor believes that one should investigate and explore the history of consumption prior to the nineteenth century in order to understand how consumption came to be seen as an attractive disease, "how the bloodspitting, coughing and the skeletal patient could be seen as desirable" (15). Similarly, in Disease, Class and Social Change: Tuberculosis in Folkestone and Sandgate, 1880-1930, Marc Arnold states that the glamorous image of tuberculosis, particularly affecting the "creative and overly sensitive", existed even before the eighteenth century (28). Therefore, it is necessary to look into the disease from the earlier times.

Going back to the sixteenth century, it can be seen that consumption was then considered a disease of desire and love (Lawlor 15). For instance, in Shakespeare's Much Ado About Nothing, Benedick's dialogue with Beatrice can clearly explain the sense of desire and love in consumption:

Benedick - Come, I will have thee, but by this light I take thee for pity.

Beatrice - I would not deny you, but by this good day I yield upon great persuasion, partly to save your life, for I was told you were in consumption (Act 5 Scene 4 200).

Lawlor argues that Beatrice's "verbal fencing" with Benedick clarifies the sense of consumptive love: the pining lovers can only be treated by possessing of what they desire; in this case, Benedick should possess Beatrice so as to continue living. Furthermore, Lawlor claims that by the time of Shakespeare, consumptive love became a "literary cliché" and "cultural given" whose convention went back to the classical times (15). Therefore, it is necessary to go back to the descriptions of consumption in classical times to better comprehend it as a disease of love. In Anatomy of Melancholy, Robert Burton tells an ancient story of a young prince named Antiochus. Antiochus oedipally falls in love with his mother-in-law, Stratonice. However, due to the impossibility of attaining his object of desire, Antiochus forcefully attempts to control his passionate feelings. As a result of suppressing his emotions, Antiochus becomes love consumptive because, according to classical medicine, suppressed emotions would lead to consumption (42). It can also be noted that many of the symptoms of the consumptive lover remain much the same from the Classical times to the Renaissance. In On the Causes and Symptoms of Chronic Diseases, Aretaeous the Cappadocian, a Greek physician, who was a very sharp observer of the disease, defines a typical consumptive type, as young, slender, probably spitting blood, coughing, weak in body, pale, narrow chested, and with winglike shoulder blades. He also describes the face as "nose sharp, 
slender; cheeks prominent and red; eyes hollow, brilliant and glittering" (qtd in Dormandy 2-3). In a similar way, Gideo Harvey, a physician to Charles II, mentions that the symptoms of a consumptive lover remained nearly the same from the time of the Classics to the Renaissance. In Morbus Anglicus: or the Anatomy of Consumptions, Harvey writes that "when Maids do suddenly grow thin-jawed and hollow-eyed, they are certainly in love" (39). He also gives a medical analysis about the violent emotions of love affecting the female body: "there is such a lingering, fighting, sobbing, and looking after the return of the absent object, the thoughts so fix'd, that they are imployed upon nothing but the vision" (39). What can be inferred here is that the only cure for a consumptive lover is the achievement of his/her object of desire. In 1598, Tofte writes about the memory of his lovesickness in a lyric sequence in which he mentions his mistress as the necessary cure. It is a typical example of the age in its expression of consumptive love.

sick is my soule, my Body languisheth,

So as I doubtfull love, scarce drawing breath,

Twixt feare and hope in the extremitie.

A strange Consumption hath me wasted long,

And for a Pearl restorative I long (qtd in Lawlor 25).

Commenting on Tofte's lyric, Lawlor writes that "Tofte gives the usual form to the figure of the languishing poetic lover who wastes away in 'a strange Consumption' caused by his mental agitation" (Lawlor 25). After considering the above examples, we get to the conclusion that consumption was a disease of love and desire, and the situation of the consumptive lover is depicted in nearly the same way in Classical and Renaissance literature.

\section{Consumption as God's Grace}

From the sixteenth to the seventeenth centuries, the second strand of the literature of consumption is the religious notion of consumption as being a disease of easy or good death. Therefore, the idea of dying from consumption was then considered desirable for the good Christian (Lawlor 28). This is because dying from consumption is a slow process: this provided the sufferers sufficient time to repent for their sins, to embrace God's grace, to prepare themselves for the eternal world, and to say farewell to their relatives. The story that follows explicitly shows the positive and pleasurable experience of dying from consumption. In The Diary of Dudley Ryder, Ryder, a law student, tells the story of his visit to a sufferer William Crisp, Ryder's friend. The story reads:

[William Crisp] is sick in bed of consumption and past hopes of recovery conversed with us. He is very serious and loves to talk of another world and to prepare for it. It is indeed a happy state when a man is got so far into religion and so far above the world as to think of passing out of it without terror and distraction, to be able to calm and serene under the assured expectation of death and leaving whatever is dear and pleasant to him. (263)

This story vividly illuminates the positive experience of dying from consumption. Crisp "loves to talk of another world and to prepare for it" (Ryder 263). Commenting on Crisp's condition, Lawlor writes that Crisp does not appear to be physically or mentally distressed by the situation he is in, "but [he is] happily fading out from this world and into the next" (29). In addition, Ryder is not the only person to find his friend's dying of consumption a pleasurable situation; his positive opinion on the disease is also clearly reinforced by Crisp's mother. Crisp's mother is so thankful to God for allowing her son die of consumption because this gives him enough time to repent for his sins (Ryder 209). Another example is Sir Thomas Browne's "A Letter to a Friend, upon the Occasion of the Death of His Intimate Friend" published posthumously in 1690 . As its title denotes, the letter describes the death of a close friend from consumption and illustrates the easy and good death from consumption:

His soft departure, which was scarce an expiration; and his end is not unlike his beginning . . . and his departure so like unto sleep, that he scarce needed the civil ceremony of closing his eyes; contrary unto the common way, wherein death draws up, sleep lets fall the eye-lids (180).

In contrast to Ryder's story of Crisp's consumption, Browne talks about the case from a doctor's standpoint. As a physician, Browne asserts that patients are not mostly aware of the fatality of consumption as they feel well and symptomless. They even have hopes of recovery: "strange it is that the common fallacy of consumptive persons, who feel not themselves dying, and therefore still hope to live, should also reach their friends in perfect health and judgment" (Browne 179). The description of dying from consumption as a "soft departure so like unto sleep" further emphasises the easiness, goodness and painlessness of the experience in dying from consumption. To Lawlor, this unique feature of consumption's "lack of pain is clearly a double edged sword": death becomes easier, without any frustration, and this makes the sufferer believe that $\mathrm{s} / \mathrm{he}$ is not in any danger. "Paradoxically, both freeing the patient from fear and withholding the possibility of action based in the truth of his condition" (Lawlor 30). To the Christians, Lawlor writes: "pain could make one peevish, alter one's state of mind or, worse still, transform one into a raving, blasphemous devil who cursed his or her nearest and dearest in the foulest language imaginable" (35). This lack of pain in consumption was a positive feature; therefore, Christians were content to die because of it. Thus, death appears as a smooth shift to Heaven, just as from "waking to sleeping- not a frightening and agonising jolt from life into death" (Lawlor 31). Mary Fissel (cited in Lawlor 32) further illuminates Lawlor's point by arguing that consumption was created to give the sufferer a chance to exhibit grace; consumption was thought to be God's doing and in one way or another advantageous to the sufferer (32). Lawlor also asserts that for many, consumption was regarded as a "Golden disease" whose unique symptomatology and religious metaphor guide the sufferers gently through their last moments and show them to be among God's chosen ones(35). The soft and easy death from consumption is explicitly manifested in Dr Samuel Garth's poem, "The Dispensary" written in 1699. The poem reads:

Whilst meagre phthisis gives a silent blow:

Her stroaks are sure, but her advances slow.

No loud alarms nor fierce assaults are shown.

She starves the fortress first, then takes the town (qtd. in Lawlor 33).

The words "silent", "slow", "No loud alarms" and "No loud fierce" signify the easiness and the goodness of dying from consumption, which was called phthisis in the 
seventeenth century. Thus, it has been made clear that in the sixteenth and seventeenth centuries, death from consumption was regarded as well-prepared, serene, good, easy and even God's grace. While medical discourse on consumption in the seventeenth and eighteenth centuries "employed extremely gruesome images of decay, putrefaction, and stinking effluvia", by the early eighteenth century there also existed "alongside the horrible pathology [. . . ] a tradition of the art of living well with, and dying a good death from consumption" (Lawlor and Akihito Suzuki 463).

\section{Female Beauty and Male Creativity}

Up to the last decades of the eighteenth century, consumption was not only associated with the metaphorical disease of the lover, or a preferred condition for the dying Christian. From then onwards consumption was also seen as the "glamorous sign of female beauty" (Lawlor 43). In this era, there was a great tendency to oppose obesity; therefore, female beauty was seen in slenderness regardless of how it was achieved, and slimness was fashionable for women. Consumption made people slender; therefore, consumption was seen as a sign of female beauty. Lawlor believes that in order to understand the reason behind this hostile position against fatness, it is worth looking into the medical ideas about the body in the eighteenth century, in which physiology of the "nerves" came into being. According to Lawlor, this "nervous sensibility" was a primary influence not only on the social and literary spheres, but also on the more broad "culture of sensibility" (44). In A Treatise on a consumption of the lungs, Edward Barry, one of the well-known physicians of the first half of the eighteenth century, defines body as a hydraulic machine made up of solids and fluids. Free circulation of fluid through the solids meant health, while obstruction of the fluid could cause putrefaction and disease. Therefore, consumption "can only proceed from a collection of purulent matter; from whence it is perpetually by the absorbent vessels received into the mass of blood, wasting the solids, and corrupting the fluids. In whatever part of the body, whether from an Ulcer, or Abscess, there is a sufficient quantity of such pus collected, a true phthisis will then ensue" (69). Barry also stresses that people in the British Isles, "particularly the better sort", are more susceptible to "an Haemoptoe [a burst blood vessel], and thence a Phthisis, from their exorbitant use of an animal diet high sauces, and spirituous liquors; their solids being naturally tender, and easily destroyed by the acrimony and velocity of the fluids" (211). This shows that the richer someone would get, the more s/he were liable to be infected by consumption as "meat and liquor agitate, accelerate and heat the blood", which increases its corrosive and "acrimonious" properties. Therefore, the best way to fight consumption is through a light, vegetarian and milky diet that cools the blood down to a safe state (188-209). Although the disease does not appear attractive here, it serves as an index of a nation's and an individual's riches. Britain, for instance, was wealthy and consumption was widespread: the upper and middle classes were the richest people in the nation; therefore, they were more likely to get infected with this disease of indulgence. Van Swieten (qtd in Lawlor 46) reiterates Barry's point by arguing that "consumption is so frequent among the English, who eat very strong food, and indulge themselves in drinking, and are less fond of vegetables than other nations."
Having discussed the cause of consumption from a medical perspective, Edward Barry in his section "Of a Consumption of the Lungs" strangely describes consumption in a beautiful way:

A national Predisposition to an Haemoptoe, may be easily distinguished by several symptoms, which are peculiar to such consumptive Constitutions, viz. a long Neck, Scapulae prominent like wings, Thorax compressed, and narrow, a clear florid Complexion, the Cheeks and lips fainted with the purest red, the Caruncle [small piece of flesh] in the Corner of the Eye, from its intense Colour, appears like Coral; and all the vesels are so fine, as to appear almost diaphanous: Such Persons are likewise most frequently remarkable for a Vivacity of Mind. (176)

Joint to Barry's description of the consumptive, Lawlor states that this description of the consumptive had also been described by the classic physicians in the same way: "long neck, wing-like upper back and thin chest." This makes it clear that Ancients also found beauty in the symptoms of consumption, which are apparent on the body of the sufferer, such as the long neck- "traditionally a prized physical asset for women" (46-47). Lawlor also justifies that consumption functioned as a natural cosmetic for women: "the face is painted with the purest red in a manner distinctly reminiscent of the courtly definition of female beauty." Here, the white colour of the skin, "clear complexion", is contrast to the red colour of the lips and the flush on the cheeks. These make consumption subject to positive aesthetic (46-47). This way, women were conceptualised in terms of a model of feminine beauty based on disease. In an essay titled "Sublime and Beautiful", Edmund Burke writes:

An air of robustness and strength is very prejudicial to beauty. An appearance of delicacy [emphasis original], and even of fragility, is almost essential to it . . . It is the flowery species, so remarkable for its weakness, and elegance. ... The beauty of women is considerably owing to their weakness, or delicacy. (112)

According to Burke, the female beauty is seen in women's weakness and fragility. Moreover, the line between sickness and "weakness" is very thin: his comparison of women with flowers that die young further emphasises the point. Samuel Jackson Pratt (25 December 1749 - 4 October 1814) emphasises the fashionability of female physical fragility in his sentimental novel Emma Corbett. He writes:

The feeblenesses to which the tender frame of women is subject, are, perhaps, more seducing than her bloom . . . in nursing which that droops (sweetly dejected) and is ready to fall upon its bed, our care becomes more dear... objects are beloved in proportion ... as they are gentle, unresisting and pathetic. (qtd in Lawlor 58)

Lawlor argues that the word " 'unresisting' is perhaps the operative word here: at least part of the vogue for female consumptiveness was inspired by the notion of well-controlled femininity, sentimentally pathetic in nervous over-refinement" (58). Thus, in the eighteenth century, far from destroying feminine beauty, consumption was considered a means of enhancing it (Lawlor 58). Female beauty was related to the consumptive look because the culture of sensibility prioritised female delicacy. This is why "the patients saw a prime occasion to beautify themselves in consumption, gaining 
individual pleasure from the admiration of others and the refined environments in which they placed themselves" (Lawlor and Akihito Suzuki 475).

What is more interesting is that consumption was not only associated with female beauty, but it was also a remark of male creativity and genius. Consumptive males were expected to be more creative, intelligent and poetic (Lawlor 44). In Tuberculosis and the Victorian Literary Imagination, Katherine Byrne describes the numerous sorts of attributes that consumption was associated with in literature: "[Consumption] has been associated simultaneously, though not always congruously, with youth and purity, with genius, with heightened sensibility" (Byrne 3). Therefore, "consumption was metaphorically purified as the ideal physical disease of sensibility" (Lawlor 44). Medical discourse also reinforced popular myths about consumption. From the doctor's perspective, Lawlor argues, consumption was also perceived as "marking individual of both sexes with some kind of special talent, particular beauty or enhanced status" (44). In the last decades of the eighteenth century, having tuberculosis, as well as "being treated for the disease became an experience associated with refined cultural values and aesthetic pleasure" (Lawlor and Akihito Suzuki 475).

5. Consumption: The Poetic Disease

Various mythologies and literary narratives of consumption have been described and analysed. These have contributed to the creation of a Romantic idea of consumption as the "glamorous disease of the beautiful and the genius" in the late eighteenth and early nineteenth centuries (Lawlor 112). In the Romantic period, consumption was seen as a poetic disease. Alexandre Dumas Wryly (qtd. in Dubos and Dubos 58-59) writes that "in 1823 and 1824, it was the fashion to suffer from the lungs; everybody was consumptive, poets especially [emphasis added]; it was good form to spit blood after each emotion that was at all sensational, and to die before the age of thirty." In "Life without Germs: Contested Episodes in the History of Tuberculosis", Gandy argues that the Romantic Movement attempted to "transform the moral stigma of the TB death into a profound experience of individual sensitivity ' which dissolved the gross body, etherealized the personality, expanded consciousness' " (19). Furthermore, consumption was treated in a positive manner in the tone of the plays, poetry and sentimental novels. However, this positive portrayal of consumption in the literary productions was not due to the author's ignorance of the realities of the disease (Lawlor 2-3). There are a number of poets and writers who despite having first-hand experiences with the disease, aestheticized consumption in their works. For example, John Keats was a primary symbolic figure of the consumptive poet whose mother and brother, Tom, died of consumption (Dubos and Dubos 12). Another typical example is Edgar Allan Poe whose wife and mother were both victims of consumption (Lawlor 3). One of the most obvious examples of Poe's romanticisation of consumption is a single paragraph in his short story "Metzengerstein." In this story, Baron Fredrick's mother, Lady Mary, dies of consumption. The narrator identifies the disease as "gentle", in which the last moments is neither painful nor gross, but "glorious." The story reads:
The beautiful Lady Mary! How could she die? - and of consumption. But I have prayed to follow. I would wish all I love to perish of that gentle disease. How glorious! To depart in the hey-day of the young blood - the heart all passion - the imagination all fire - amid the remembrances of happier days in the fall of the year, and so be buried up forever in the gorgeous, autumnal leaves. Thus died Lady Mary. (Poe 97)

The phrase "autumnal leaves" denotes the romantic image of consumption: "autumn was traditionally the time for consumptive death, but also the most visually poetic of seasons" (Lawlor 2). Furthermore, according to Dormandy, the image of falling leaves, in the literature of consumption, was a symbol for "failing hopes [and] the destruction of young lives" (85). Like John Keats, Poe reveals the "terrible beauty of consumption" in spite of his exposure to the harsh realities of the disease (Dormandy 93). Nevertheless, "Metzengerstein" does not show consumption as painful and/or horrible, but as easy and painless. Moreover, Poe describes the death of the beautiful Lady Mary as a "glorious" one. He also goes as far as wishing "all [he] love[s] to perish of that gentle disease" (Poe 97). Poe's romanticisation of consumption in his literary productions is in parallel to his contemporary writers' attitude towards the disease. One of the typical literary writings in which a romantic idealisation of consumption can be felt is Charlotte Brontë's autobiographical novel Jane Eyre published in 1847. Like Poe, Brontë had a number of first-hand experiences with the disease. In fact, her family history with consumption is one of the typical, tragic examples of what was called "familial phthisis" (Carpenter 55). All of Reverend Patrick Brontë's six children died of consumption: Anne and Maria Brontë died in May and June of 1825; Branwell in September 1848 and Emily in December of the same year. Anne Brontë died of the same disease in May 1849. Charlotte Brontë outlived her siblings; she died in 1855 when she was 39 years old (Carpenter 54). Despite Charlotte Brontë's tragic experiences with the disease, she features one of the consumptive child characters, Helen Burns in her novel Jane Eyre. Helen Burns is the representation of the archetypical consumptive child who is too good, pure and innocent for this sinful Earth. In fact, from the mid-eighteenth until the midnineteenth century "the dying tubercular maiden would be represented commonly in all media and genres as a beautiful bride of heaven, an angel too pure and spiritualised to abide long in the material world of the crude body and less-refined ones" (Lawlor and Akihito Suzuki 479). When on the verge of death and is accompanied by Jane, the main character, Helen Burns says:

I am very happy, Jane; and when you hear that I am dead, you must be sure and not grieve; there is nothing to grieve about. We all must die one day, and the illness which is removing me is not painful; it is gentle [emphasis added] and gradual; my mind is at rest. I leave no one to regret much; I have only a father; and he is lately married, and will not miss me. By dying young, I shall escape great sufferings. I had not qualities or talents to make my way very well in the world; I should have been continually at fault. (Brontë 97)

Helen does not suffer from pain. She is described as having a "fit of coughing" that makes her "lay some minutes exhausted" (Brontë 97). In addition, her passing away is portrayed as being very "gentle". As Catherine Byrne 
describes, Helen is "a Christlike portrait of resigned, uncomplaining suffering, and it is notable that her death, from consumption has more meaning . . . than those of dozens of others who die around her in the typhoid epidemic" (16). Helen is among the "angelic, too-good-to-live child heroes" in the literature of the nineteenth century (16).

In Disease, Class and Social Change: Tuberculosis in Folkstone and Sandgate, 1880-1930, Mark Arnold states that during the second half of the eighteenth and the early nineteenth centuries, the romantic idealisation of the consumptive life and death affected many of the patients to integrate the disease into their identity as a "disease of the self" (28). In Illness as Metaphor, Susan Sontag analyses the paradoxical nature of consumption. By comparing consumption to cancer, she realises a sharp contrast in the metaphors generated by the two lethal diseases. Whereas consumption served as a metaphor of basically positive features, such as refined sensibility, heightened beauty and artistic creativity, cancer stood for the negative values. In this regard, Tuberculosis was identified as the disease of the self while cancer was considered the disease of the Other (66). English and the American culture in particular incorporated the disease into the self, due to the apparently positive and attractive attributes of the disease. Lawlor and Akihito Suzuki also argue that "diseases of the Self are more commonly found in certain diseases of a relatively mild nature, which were sought as badges of the social and cultural distinction of the sufferers" (459). Therefore, people considered these diseases as being a part of their identities. This made them endure living with the painful and horrible symptoms of the diseases. More interestingly, a paradoxical sense can be perceived in the case of consumption. Despite its fatality, especially in the eighteenth and the nineteenth centuries, the romantic appeal of consumption has been noted not only by the historians of medicine and literature, but also by the sufferers themselves (460-461). Moreover, Lawlor and Akihito Suzuki argue that "consumption, like the Romantic myth of the alienated or narcissistic self, is obviously part of a social totality, but it is comparatively less 'othered' than cancer or, to take a major example from the eighteenth century, smallpox" (459-460).

As the nineteenth century progressed to the twentieth, the aestheticised image of consumption declined. The first nail in the coffin of the ideal romanticisation of consumption came in 1882 when the German Bacteriologist Robert Koch discovered the causative agent of the disease: the Mycobacterium tuberculosis. Koch's discovery "produced such a phenomenal sensation among the lay public and in medical circles that it was immediately regarded as... heralding a new era in the study and control of disease" (Dubos and Dubos 102). After Koch's discovery, consumption was "no longer a vague phantom. The heretofore unseen killer was now visible as a living object and its assailants at last had a target for their blows" (102). The tuberculosis bacillus was merely a germ which could be contracted by anyone (Lawlor 186-187). Koch's findings faced some resistance - some refused to believe Koch and attempted to prove his findings wrong. However, these "unbelievers were fighting a losing battle" (Dormandy 136). After Koch, there was no cure for the disease - "effectible respite would not be available until the mid-twentieth century" (Lawlor 187). Myths about the romantic idealisation of the disease persisted even after Koch, but this aestheticised image began to decline and it vanishes completely by the mid twentieth century." The praise of the spiritualised women fading into God's glory [such as Helen burns] is rarely, if at all, to be found after 1880." Literature of the twentieth century embraced illness as a sign of the outsider. Tuberculosis was no longer a disease of the Self, but a disease of the Other (Lawlor 189). Gradually, the negative picture of the disease as a danger to the wellbeing of the public was illuminated. In addition, in some countries and cities governments and voluntary organisations fought against tuberculosis in the hope of eliminating it (Lawlor and Akihito Suzuki 460-461).

6. Conclusion

Consumption had the most recognisable personality of all the diseases portrayed in literature. Throughout its history, it was known as a disease of love, desire, romance, emotion, grace, beauty, creativity and intellectualism. A killer disease which caused the death of one in four people in America and Western Europe from the seventeenth to the nineteenth century (Lawlor 5) was presented as an ideal way to die. The sufferers were praised for their beautiful and productive death, and the consumptive young women and children were thought to be spirited away to heaven in the gentlest way. Moreover, this romantic idealisation of the disease made people integrate the disease into their identities as the disease of the "Self." Among the sufferers were the most well-known and prominent writers who had tragic experiences with the disease, yet they believed in the myths of consumption and treated it positively in their literary works. However, with the rise of science, the romanticised image of consumption began to decline. It was later became a force to be defeated, rather than celebrated. It no longer made one to achieve special creative qualities, but the modern victim of tuberculosis is merely diseased, who needs to be treated, otherwise s/he would die a terrible death.

\section{Works Cited}

Arnold, Marc. Disease, Class and Social Change: Tuberculosis in Folkestone and

Sandgate, 1880-1930. Newcastle: Cambridge Scholars Publishing, 2012. Print.

Barry, Edward. A Treatise on a consumption of the lungs. Dublin: George Grierson. Print.

Brontë, Charlotte. Jane Eyre. New York: Barnes \& Noble Classics, 2005. Print.

Browne, Thomas. "A Letter to a Friend, upon the Occasion of the Death of His Intimate Friend." Sir Thomas Browne: Religio Medici and Other Works. Ed. L. C. Martin. Oxford: Clarendon Press, 1964. Print.

Burke, Edmund. "Sublime and Beautiful." A Philosophical Enquiry into the Origin of Our Ideas of the Sublime and Beautiful. Ed. Adam Phillips. Oxford: OUP, 1990. Print.

Burton, Robert. The Anatomy of Melancholy. Ed. Homas C. Faulkner, Nicolas K. Kiessling, Rhonda L. Blair. Vol. I. Oxford: OUP, 1989. Print.

Byrne, Katherine. Tuberculosis and the Victorian Literary Imagination. 
Cambridge: Cambridge UP, 2011. Print.

Carpenter, Mary Wilson. Health, medicine, and Society in Victorian England. Santa Barbara, CA: Praeger, 2010. Print.

Dormandy, Thomas. The White Death: A History of Tuberculosis. London: Hambledon Press, 1999. Print

Dubos, René and Jean Dubos. The White Plague: Tuberculosis, Man and Society.

London: Lowe and Bydone, 1953. Print.

Gandy, Mathew. "Life without Germs: Contested Episodes in the History of

Tuberculosis." The Return of the White Plague: Global Poverty and the New Tuberculosis. Ed. Mathew Gandy and Alimuddin Zumla. London: Verso, 2003. 15-39. Google books. Web. 28 May 2016.

Harvey, Gideon. Morbus Anglicus: or the Anatomy of Consumptions. London: Nathanael Brook, 1666. Print.

Lawlor, Clark and Akihito Suzuki. "The Disease of the Self: Representing

Consumption, 1700-1830." Bulletin of the History of Medicine 74.3 (2000): 614-615. Project Muse. Web. 28 June 2016.

Lawlor, Clark. Consumption and Literature: The Making of the Romantic Disease.

Hampshire: Palgrave MacMillan, 2007. Print.

Poe, Edgar A. "Metzengerstein." Southhern Literary Messenger.(1835): 97-100. Google Books. Web. 12 July 2016. Ryder, Dudley. The Diary of Dudley Ryder, 1715-1716. Transcribed from shorthand and Ed. William Mathews. London: Methuen, 1939. Print.

Shakespeare, William. Much Ado About Nothing. Ed. Sheldon P. Zitner. Oxford:

Clarendon Press, 1993. Print.

Sontag, Susan. Illness as Metaphor and AIDS and Its Metaphors. New York:

Picador, 2001. Print. 